\title{
'Dirty foreigners' are to blame for COVID-19: impacts of COVID stress syndrome on quality of life and gratitude among Singaporean adults
}

\author{
Chin-Siang Ang ${ }^{1,2}$. Arul Anand Eric Lucio Erucio Das S/O A Sudha Ann Nancy ${ }^{3}$
}

Accepted: 22 November 2021

(c) The Author(s), under exclusive licence to Springer Science+Business Media, LLC, part of Springer Nature 2021

\begin{abstract}
The outbreak of COVID-19 has caused widespread emotional distress. The current study sought to ascertain the impact of COVID stress syndrome on quality of life and gratitude. The COVID-19 Stress Scale, COVID-19 Quality of Life Scale, and Gratitude Resentment and Appreciation Scale were administered to 199 Singaporeans. Data were collected online using convenience sampling between December 2020 and March 2021. Pearson correlations and hierarchical regression analyses were used to test the research hypotheses. The results showed that fear of spreading SARSCoV2 by foreigners was the most stressful fear among Singaporeans $(M=2.59)$, while traumatic stress by COVID-19 was the least stressful fear $(M=0.16)$. COVID stress syndrome was positively correlated with negative quality of life ( $r$ ranged from .25 to .66$)$ and negatively correlated with gratitude ( $r$ ranged from -.29 to -.14 ). Xenophobia was also found to be the most influential factor in reducing quality of life $(\beta=.52)$ and gratitude $(\beta=-.37)$ during the pandemic. Study findings demonstrate how COVID-19 increases Singaporeans' xenophobic attitudes towards foreigners, making them more vulnerable to the pandemic.
\end{abstract}

Keywords COVID stress syndrome $\cdot$ Gratitude $\cdot$ Quality of life $\cdot$ Singapore $\cdot$ Xenophobia

\section{Introduction}

Unlike previous viral outbreaks such as Severe Acute Respiratory Syndrome (SARS), which spread mainly in hospitals, SARS-CoV-2 virus (COVID-19) has spread far beyond the confines of health centres (Kang et al., 2020). Chills, fever, cough, headache, sore throat, nausea, vomiting, and diarrhoea are all possible symptoms of this infection. Severe cases of the disease can lead to heart failure, respiratory failure, or even death. COVID-19, in addition to physical symptoms, can also have serious consequences for mental health (Xiong et al., 2020). Following the virus's spread, it quickly became a global threat to public health, leading to

Chin-Siang Ang

austin_ang119@hotmail.com

1 School of Psychology, TMC Academy, 805 Geylang Rd, 389683 Singapore, Singapore

2 Centre for Population Health Sciences, Lee Kong Chian School of Medicine, Nanyang Technological University, 11 Mandalay Rd, Singapore 308232, Singapore

3 Faculty of Health, Education and Society, The University of Northampton, Waterside Campus, University Drive, Northampton, NN1 5PH, UK an unprecedented state of fear and uncertainty (Liu et al., 2020). Changes in daily routines, such as mandatory wearing of masks in public, restrictions on movement, social distancing, and loss of income, appear to be particularly stressful (Harvey et al., 2020; Kampf et al., 2020; Lu et al., 2020). Other stressors include bereavement, fear of infection, travel bans, and orders to work from home (Ren et al., 2020; Wu et al., 2021). While the fear response is an important adaptive mechanism that humans have evolved to use in response to environmental threats, it may only be useful for those who believe they can cope with the threats they face (Ang, 2020). For those who believe they are unable to cope with such risks, fear can be a critical condition associated with mental disorders.

\section{COVID-19 in Singapore}

The first COVID-19 case was reported in late 2019 in Wuhan, China (Lu et al., 2020). The disease then spreads rapidly throughout the region (Centers for Disease Control and Prevention [CDC], , 2021). Due to the steady increase in infections and deaths, the World Health Organization (2020) declared a global pandemic. By September 30, 2021, $234,304,776$ people had been infected and over $4,791,753$ 
people had died from the disease (Worldometer Statistics, 2021). In response to the pandemic, many governments have enacted strict laws to prevent the spread of the disease (Xiong et al., 2020). Some of the worst-hit countries, such as China, Belgium, Italy, France, and Spain, have imposed long periods of self-isolation and/or lockdown and told citizens to stay home, severely impacting the quality of life for the population. Uncertainty about how the disease will spread and develop, as well as the lack of an effective vaccine to combat the disease, are increasing public fear (Harvey et al., 2020; $\mathrm{Wu}$ et al., 2021). There is growing clinical evidence of the impact of COVID-19. According to data from a systematic review of 19 research studies (Xiong et al., 2020), depression $(14.6 \%-48.3 \%)$, anxiety $(6.33 \%-50.9 \%)$, and stress $(8.1 \%-81.9 \%)$ were present in varying and often elevated levels. Furthermore, a COVID-19 crisis poses significant challenges for vulnerable populations who live in developing or underdeveloped countries, have a pre-existing health condition, are female or unemployed, or are younger than 40 years old. Considering that mitigation efforts vary greatly across countries, the authors emphasize the importance of determining whether these effects are also observed in other countries.

Singapore, as one of the world's most densely populated countries (8358 people per $\mathrm{km} 2$ ), is particularly vulnerable to the COVID-19 virus (Ngiam et al., 2021). In fact, as of 30 September 2021, Singapore had 94,043 confirmed cases with 93 deaths ( $0.002 \%$ of the population), indicating lower transmission and mortality (Worldometer Statistics, 2021). In addition, Singapore's fight against the spread of COVID19 has been internationally recognized for demonstrating its ability to manage resources and crisis management, as well as efficiently detect and isolate new cases ("Singapore tops ranking", 2021). On 24 January 2020, Singapore announced the first case of COVID-19 (Tan et al., 2020). In February, Singapore raised the Disease Outbreak Response System Condition (DORSCON) status to Orange, causing panic buying. Supermarkets were suddenly out of toilet paper and instant noodles. Singapore reported its first COVID-19 death in March 2020, following local transmissions and clusters. As the virus spread in migrant workers' dormitories, the number of confirmed cases skyrocketed, and the government scrambled to track down and isolate all affected workers (Bagdasarian \& Fisher, 2020; Tan et al., 2021).

As a result, the restrictions were tightened even more. From 3 April to 1 June 2020, the Circuit Breaker was in place to prevent the spread of COVID-19 infections (Ministry of Health Singapore, 2020). People's movement was restricted during this time, non-essential businesses were closed, and school classes were moved entirely online. Every suspected case was thoroughly investigated, and anyone who had come into contact with confirmed cases was tracked down and confined to their homes for the duration of the release (Ngiam et al., 2021). Many dormitories were quarantined, effectively locking workers in. Although the vaccine is currently being aggressively administered, the focus remains on wearing a mask and practicing good hygiene, as well as social distancing. Given the rise in confirmed cases in migrant workers' dormitories (Lee et al., 2020; Tan et al., 2020), this study examines COVID stress syndrome and its psychological impacts on the general population in Singapore.

\section{COVID-19 Pandemic and Stress Syndrome}

When assessing the emotional and psychological impact of the pandemic, stressors must be considered (Wu et al., 2021; Xiong et al., 2020). Taylor et al. (2020) developed a scale to assess five types of stress related to the pandemic, including fear of danger and contamination, socioeconomic status consequences, xenophobia, compulsive checking and seeking assurance, and traumatic stress reactions, after recognizing that COVID-19 could trigger a variety of life stressors. The five facets of the COVID stress syndrome, according to Taylor et al. (2020), are correlated, which means that each type of stress influences the others.

Danger and Contamination COVID-19 is a new and unknown disease, with a high mortality rate and rapid spread (Lu et al., 2020). According to Perrin et al. (2009), fear is a common response to a contagious epidemic, leading to increased anxiety and hypervigilance. During the SARS pandemic, about $70 \%$ of Hong Kong residents were more concerned about contracting SARS than about getting the common flu. Despite the possibility of surface transmission, the risk of contracting COVID-19 is considered low. Scientists have gathered evidence that surface transmission of SARS-CoV-2 is not the primary route of transmission as the pandemic has progressed (Harvey et al., 2020; Kampf et al., 2020). In May 2021, the CDC (, 2021) clarified its guidance on surface transmission, stating that it is not the primary route of transmission. Instead, COVID-19 appears to be spread primarily through respiratory droplets released when sneezing, coughing, or talking. Infected droplets can enter an exposed person's eyes, nose, or mouth either directly or indirectly through contaminated surfaces (Harvey et al., 2020; Kampf et al., 2020). People in close proximity may directly inhale them. Precautions such as consistent and proper use of masks, hand hygiene, cleaning, and maintaining a clean environment can all be taken to reduce the risk of contamination.

Socioeconomic Status Socioeconomic status is also a domain of COVID stress syndrome. Most countries chose to implement a lockdown to prevent COVID-19 from spreading to the general public (Poudel \& Subedi, 2020). Non-essential 
travel, as well as many non-essential businesses, were prohibited, and employees were required to work from home (Kampf et al., 2020). Widespread job losses, significant reductions in work hours, and significant wage cuts all point to a sharp drop in economic activity (Pfefferbaum \& North, 2020). In contrast to the global financial crisis of 20082009 , the International Labour Organisation (, 2020) predicted that 25 million jobs will be lost globally by the end of 2020, two million more than during the crisis. Nonetheless, economic downturns vary by socioeconomic status. According to Heath (2020), $45 \%$ of people in the upper socioeconomic status were concerned about their household finances and overall economic well-being since the pandemic began. Agberotimi et al. (2020) found that $62 \%$ of participants in the middle socioeconomic group were depressed due to job insecurity and financial anxiety. Because it is more difficult for low-income adults to work from home, they were disproportionately affected by coronavirus-related job loss or pay cuts. According to some studies, unemployment and job loss were major factors that harmed people's mental health (Gallo et al., 2000). Furthermore, job insecurity was considered an aetiology of unwellness (Wu et al., 2021) and depression (Agberotimi et al., 2020). .

Xenophobia Fear of foreigners or migrants, also known as xenophobia, is a broad term that refers to prejudice or hatred of people from other countries (Yi et al., 2021). It is most often used to describe discrimination against immigrants and foreigners. The threat of a health crisis is thought to elicit xenophobic sentiments, which manifest as varying degrees of racial discrimination. Since the January 2020 outbreak of COVID in China, many reputable news organizations have reported instances of racism against ethnic Chinese and other Asians (Chui, 2020). Stop AAPI Hate, a group of online activists, received nearly 2800 reports of discrimination against Asian Americans in October 2020 (Rich, 2020). This is not uniquely American phenomenon. In the United Kingdom, the number of hate crimes committed against people of Chinese and East Asian descent has increased by 300\% (World Health Organization, 2020). Human Rights Watch documented a number of cases of xenophobia and discrimination in Indonesia, Italy, the Middle East, and Russia (Pedrosa et al., 2020). As long as COVID-19 is referred to as the "Chinese virus," people can blame or despise anyone who resembles a Chinese person for their losses (Ren et al., 2020). In fact, xenophobia is not a new phenomenon, as evidenced by previous epidemics (Han et al., 2018; McCauley et al., 2013). When Ebola broke out in the United States in 2014, for example, African immigrants living there were subjected to hurtful questions and outright violence (Monson, 2017).
Checking Behaviours and Seeking Assurances According to Boelen and Carleton (2012), uncertainty plays an important role in obsessive-compulsive behaviours. Fear of a pandemic causes obsessive control and security-seeking behaviour (Jassi et al., 2020). People seeking certainty and security may search online or social media for information about the symptoms of the virus or the news for the most current information (Taylor et al., 2020). However, excessive attention to social networking or media can lead to psychological distress (Arndt et al., 2004). It has been shown that those who pay the most attention to COVID-19 news were more anxious (Liu et al., 2020). In general, the news posted on COVID-19 is upsetting and sometimes accompanied by rumours, causing people to become more anxious as a result of constant exposure to COVID-19 news. Various false reports on COVID-19 can aggravate anxiety symptoms and lead to maladaptive coping behaviours. This condition can result in excessive hand washing, panic buying, and a buildup of hand sanitizer, toilet paper, and cleaning wipes (El-Terk, 2020). These phenomena were more prevalent in the groups with lower levels of education due to unreliable access to information in an epidemic context (Pfefferbaum \& North, 2020).

Traumatic Stress Traumatic stress, also known as posttraumatic stress disorder (PTSD), is a mental disorder caused by trauma (American Psychiatric Association (2013). People suffering from PTSD often have flashbacks and nightmares of the trauma, avoid situations or people that trigger the memory, show negative emotions such as hostility, low selfesteem, distrust, or withdrawal, and have difficulty sleeping or concentrating. Despite modern medical advances, COVID19 has killed over a million people in less than a year (World Health Organization, 2020). The pandemic has also resulted in significant emotional and psychological difficulties such as social isolation, fear of illness, loss of a loved one, unemployment, and financial insecurity (Bridgland et al., 2021; Pfefferbaum \& North, 2020). Anxiety, depression, PTSD, and other trauma- and stress-related disorders can result from these events. The risk increases when selfquarantined individuals do not have immediate access to social support. A study of Chinese adolescents quarantined at home during the first month of the COVID-19 outbreak found that $12.8 \%$ of them exhibited PTSD symptoms that led them to adopt a negative coping style (Liang et al., 2020). Symptoms were expected to worsen as the quarantine period progressed. Nonetheless, people respond to trauma differently, and trauma affects them differently. PTSD does not affect everyone who has been exposed to trauma or the pandemic, and it is influenced by a number of factors, such as the severity of illness, symptoms, age, and support (Wang et al., 2020). 


\section{COVID Stress Syndrome, Quality of Life, and Gratitude}

Quality of life (QOL) is a measure of satisfaction that involves value judgments: The general or specific experience of life is rated as good or bad (Cella, 1994). This concept broadly encompasses all human experiences in relation to the necessities of life and can be defined as a measure of how happy or satisfied they are with their life in general (Repišti et al., 2020). Previous large-scale outbreak studies have found that negative emotions like anxiety and stress have a negative impact on QOL (Pedrosa et al., 2020). During the COVID-19 pandemic, $31.4 \%$ of people experienced depression and $31.9 \%$ experienced anxiety, according to a meta-review of 66 studies (Wu et al., 2021). Loss of a loved one, loss of income, negative media coverage, mobility restrictions, and inadequate government responses may all exacerbate fear and distress (Kang et al., 2020; Poudel $\&$ Subedi, 2020).

The COVID stress syndrome is likely to play an important role in determining a person's QOL during the pandemic. COVID stress syndrome is caused by more than just the fear of the infection of COVID-19(Ren et al., 2020; Taylor et al., 2020). Economic, health, psychological, and social bottlenecks in a pandemic can have a significant impact on QOL (Wu et al., 2021). As previously stated, the pandemic has restructured many aspects of daily life, and the resulting stress has had a negative impact on all individuals (Wang et al., 2020). Because such a pandemic has never occurred globally, it is unknown how or to what extent the stress syndrome will affect QOL. As the pandemic could last longer than expected, studying the relationship between variables could help in the development of prevention and intervention strategies (World Health Organization, 2020).

Gratitude is defined as a positive feeling of thankfulness for what one receives, whether it is tangible or intangible. A gratitude act consists of consciously noticing joy, appreciation, and thankfulness in a given situation (Alkozei et al., 2018; Emmons \& McCullough, 2003). Gratitude has been shown in studies to be beneficial in many ways. According to Wood et al. (2010), gratitude can help people reduce stress and worry, lowering their risk of mental health problems. It was also found that gratitude motivates people to be sensitive to others and helpful. In the Oliveira et al.'s (2021) study, feeling grateful can lead to more cooperation, which increases positive affect and empathy while decreasing negative affect. Gratitude has also been shown in a number of studies to reduce the impact of negative experiences and events. One study found that veterans with higher levels of gratitude experienced fewer symptoms of PTSD, had stronger positive affect, and felt more self-worth (Kashdan et al., 2006). In addition, a 2015 Israeli study found that gratitude exercises can improve traumatic stress, emotional well-being, and life satisfaction in rocket attack survivors (Israel-Cohen et al., 2015). In the midst of a crisis as allencompassing as COVID-19, many people experienced additional stress and a collective sense of loss (e.g., of safety, security, and connections). People seem to turn to gratitude more than any other positive emotion during a pandemic (Tong \& Oh, 2021). Practicing gratitude provides people with the energy and ability to heal, hope, and overcome obstacles. In the study, gratitude was linked to greater resilience to stress in general and support for antiviral interventions, which resulted in better positive coping with the pandemic (Tong \& Oh, 2021). Jans-Beken (2021) also suggested that practicing gratitude can help to cope with stress and stay healthy during the pandemic. Despite the fact that there is a consistent negative relationship between stress and gratitude, much of this research has focused on gratitude as an intervention or practice (Israel-Cohen et al., 2015; Kashdan et al., 2006; Oliveira et al., 2021). It is certainly useful to consider gratitude as a form of intervention, but we believe that gratitude also has a trait component, similar to individual differences (Emmons \& McCullough, 2003). People may become less or more grateful over time and under different circumstances, such as COVID-19. Our literature review revealed that very few studies have been conducted to examine the effects of stress on the trait of gratitude. In this study, gratitude is examined as a disposition, a trait-like characteristic.

\section{The Present Study}

Following a review of the emerging pandemic literature, it is clear that more research is needed to identify predictors of quality of life and gratitude during the pandemic. There is also evidence in the literature that sociodemographic variables such as gender, age, education, relationship status, and income influence study variables. Since most studies have focused on health care workers (Cabarkapa et al., 2020; De Kock et al., 2021; Muller et al., 2020; Teo et al., 2020), little attention has been paid to the impact of the COVID19 pandemic on the general population, despite the fact that the virus will be with us for the foreseeable future. To determine whether the COVID-19 crisis and an outbreak in migrant worker dormitories had a negative impact on stress symptoms and psychological outcomes, we aimed to measure levels of COVID-19-related stress, quality of life, and gratitude in the general Singaporean population and test a regression model with variables related to quality of life and gratitude. It was hypothesized that COVID stress syndrome would be negatively and directly associated with quality of life and gratitude after controlling for sociodemographic variables. 


\section{Method}

\section{Design}

In pursuit to test the previously described research hypotheses, data from a cross-sectional study were collected using convenience sampling. The collected data were then used in analytical computation to scientifically explain the relationships between study variables. The cross-sectional study is widely regarded as the most appropriate method for gathering data in correlational research.

\section{Measures}

COVID-19 Stress Scale (COVID19-SS; Taylor et al., 2020) To assess COVID-related stress, the 36-item COVID19-SS was used. The scale is composed of 5 subscales: Danger and Contamination Fears (12 items), Fears on Economic Consequences (6 items), Xenophobia (6 items), Compulsive Checking and Reassurance Seeking (6 items), and Traumatic Stress (6 items). The Danger and Contamination Fears subscale measures one's feelings and concerns about the threat of the virus and the possibility of being infected by people or objects touched by others (e.g., I am worried about catching the virus and I am worried that people around me will infect me with the virus). The Fears on Economic Consequences subscale measures a person's anxious feelings about the lack of essential supplies in grocery stores (e.g., I am worried about grocery stores running out of food). The Xenophobia subscale measures a person's level of concern about foreigners (e.g., I am worried that foreigners are spreading the virus in my country). The Compulsive Checking and Reassurance Seeking subscale measures the frequency of checking news related to the Covid-19 pandemic (e.g., how much have you checked social media posts concerning COVID19). The Traumatic Stress subscale measures the amount of stress a person feels due to the pandemic (e.g., I had bad dreams about the virus). Participants were asked to respond to the items on a 5-point Likert-type scale ranging from $0=$ not at all to $4=$ extremely. Higher mean scores indicate greater anxiety. The scale has been shown to be valid and reliable when used with adult populations in Canada and the United States (Taylor et al., 2020). In this study, Cronbach's coefficient alphas were .95 for danger and contamination, .92 for economic consequences, .94 for xenophobia, .75 for traumatic stress, and .72 for checking behaviour.

COVID19 -Quality of Life Scale (COVID19-QoL; Repišti et al., 2020) The COVID19-QoL was used to assess the unidimensional structure of QOL in the general population during the COVID-19 pandemic (e.g., Due to the spread of coronavirus, I think my quality of life is lower than before). The six items of the scale were rated on a 5-point Likert-type scale ranging from $1=$ completely disagree to $5=$ completely agree. Higher mean scores indicate lower quality of life. The scale has been shown to have good psychometric properties (Repišti et al., 2020). In this study, the Cronbach's coefficient alpha was .88 .

Gratitude Resentment and Appreciation Scale (GRAT; Watkins et al., 2003) The GRAT is a measure of global dispositional gratitude and consists of 10 items. In this study, the scale was slightly adapted to measure gratitude in the midst of the pandemic (e.g., Amid the pandemic, I couldn't have gotten where I am today without the help of many people). Participants rated each item on a 7-point Likert-scale ranging from strongly disagree to strongly agree. Higher mean scores indicate more gratitude. The validity and reliability of the scale have been demonstrated (Watkins et al., 2003). In this study, the internal consistency of the scale was reported to be .79 .

\section{Procedure}

Permission to conduct the research was obtained from the University of Northampton Psychology Ethics Committee (Study Code: 21403016). Data were collected online between December 2020 and March 2021. Several social media platforms were used to collect as diverse sample as possible. Prior to conducting the survey, an information sheet describing the study was provided to all potential participants. Participants were asked to complete an informed consent form if they chose to participate. After receiving the consent form, participants were directed to the online survey. On average, it took participants approximately 20-25 min to complete the surveys. Upon completion of the survey, participants were debriefed and thanked for their participation. All participants took part voluntarily and were not compensated for their participation. The General Data Protection Regulations (GDPR) 2018 were followed when handling the data. Data from the anonymised survey was kept confidential in a password-encrypted spreadsheet. The data could only be accessed by the research team. No other parties were permitted access.

\section{Data Analysis}

Statistical Package for the Social Sciences (SPSS) software was used to analyze the data (SPSS, version 26). Descriptive statistics were used to examine the sociodemographic characteristics of the participants. Descriptive analyses were also conducted using the COVID19-SS, COVID19-QoL, and GRAT instruments to determine the stress level, quality of life and gratitude of the study participants. Pearson 
correlations were used to assess the correlations between the instrument scores. Finally, hierarchical regression analyses were conducted to examine the prediction of COVID19 stress syndrome on two dependent variables, quality of life and gratitude, taking into account sociodemographic controls. In the first step, (1) age, (2) gender (dummy variable, female $=1$, male $=0$ ), (3) race (dummy variable, Chinese $=1$, non-Chinese $=0$ ), (4) education (dummy variable, college and higher $=1$, lower than college $=0),(5)$ marital status (dummy variable, married $=1$, all others $=0$ ), (6) income, and (7) number of dependents were entered. COVID stress syndrome including danger and contamination, socioeconomic status, xenophobia, traumatic stress, and checking behaviours were added in step two. A number of assumptions were also checked, including normality, collinearity, homoscedasticity, independent errors, and linearity.

\section{Results}

\section{Sample Demographic}

As can be seen in Table 1, the sample is both adequate $(n=199)$ and diverse. The sample is balanced in respect to gender and exhibits good diversity in regard to age (ranged from 23 to 52 years old), income (ranged from 2400 to 25,000 ), number of dependents (ranged from 0 to 6 ), ethnicity, marital status, and education, About $7 \%$ of participants

Table 1 Sample Characteristics

\begin{tabular}{|c|c|c|}
\hline Demographic Variable & Frequency (Mean) & $\begin{array}{l}\text { Percentage } \\
\text { (Standard } \\
\text { Deviation) }\end{array}$ \\
\hline Age & $(35.75)$ & (5.67) \\
\hline Monthly Household Income & $(5606.53)$ & (3883.07) \\
\hline Number of Dependents & $(0.80)$ & $(1.04)$ \\
\hline \multicolumn{3}{|l|}{ Gender } \\
\hline Female & 91 & 45.7 \\
\hline Male & 108 & 54.3 \\
\hline \multicolumn{3}{|l|}{ Race } \\
\hline Chinese & 125 & 62.8 \\
\hline Indian & 28 & 14.1 \\
\hline Malay & 46 & 23.1 \\
\hline \multicolumn{3}{|l|}{ Highest Level of Education } \\
\hline Diploma & 30 & 15.1 \\
\hline Bachelor's Degree & 157 & 78.9 \\
\hline Master's Degree & 12 & 6 \\
\hline \multicolumn{3}{|l|}{ Marital Status } \\
\hline Divorced & 10 & 5 \\
\hline Married & 61 & 30.7 \\
\hline Partnered & 45 & 22.6 \\
\hline Separated & 17 & 8.5 \\
\hline Single & 66 & 33.2 \\
\hline \multicolumn{3}{|c|}{ Have any of your friends or family tested positive for COVID-19? } \\
\hline No & 198 & 99.5 \\
\hline Yes & 1 & 0.5 \\
\hline \multicolumn{3}{|c|}{ Are you working remotely as of recent due to COVID-19? } \\
\hline No & 185 & 93 \\
\hline Yes & 14 & 7 \\
\hline \multicolumn{3}{|c|}{ Did you lose your job or any wages because of the COVID- $19 ?$} \\
\hline No & 189 & 95 \\
\hline Yes & 10 & 5 \\
\hline \multicolumn{3}{|c|}{$\begin{array}{l}\text { Do you believe that the measures the government has taken are } \\
\text { enough to contain the spread of coronavirus? }\end{array}$} \\
\hline No, should be stricter & 5 & 2.5 \\
\hline Yes, are about right & 193 & 97 \\
\hline Yes, but are too strict & 1 & 0.5 \\
\hline
\end{tabular}


reported having to work remotely and $5 \%$ of participants reported losing their job or salary due to COVID-19. Only $0.5 \%$ of participants reported having family members or friends who tested positive for COVID-19. However, 97\% of participants felt that the measures taken by the government were sufficient to contain the spread of the coronavirus.

\section{Descriptive Statistics}

Table 2 shows the ranges, means, and standard deviations for all total scales in this study. In general, COVID stress syndrome were positively skewed, as most participants tended to report low scores, with the exception of xenophobia. Regarding the negative impact of quality of life, participants, on average, provided a moderate score. Nevertheless, the rating of gratitude was negatively skewed. In other words, participants generally gave higher scores on the gratitude items. The skewness of these scales ranged from -0.67 to 1.91; the kurtosis ranged from -1.09 to 2.82 , so the data obtained can be considered normally distributed.

\section{Correlations between Study Variables}

Table 3 shows the correlations between the variables in the study. Overall, all COVID-stress subscales were positively correlated. Participants who reported higher scores in one stress-related domain also reported higher scores in another stress-related domain. All COVID-stress subscales were

Table 2 Descriptive Statistics

\begin{tabular}{lllll}
\hline Variable & Mean & Std. Deviation & Skewness & Kurtosis \\
\hline $\begin{array}{l}\text { Danger \& Contamina- } \\
\text { tion }\end{array}$ & 0.61 & 0.69 & 0.66 & 2.42 \\
Socioeconomic Status & 0.28 & 0.58 & 1.77 & 2.82 \\
Xenophobia & 2.59 & 1.05 & 0.44 & -1.09 \\
Traumatic Stress & 0.16 & 0.13 & 1.91 & 2.01 \\
Checking Behaviour & 0.94 & 0.48 & 1.69 & 1.91 \\
Negative QoL & 2.26 & 0.73 & 0.23 & -0.19 \\
Gratitude & 5.56 & 0.59 & -0.67 & 1.78 \\
\hline
\end{tabular}

positively related to negative quality of life. The results indicated that the higher the stress relevant to COVID-19, the greater the negative impact on participants' quality of life. However, only danger and contamination and xenophobia subscales were negatively associated with gratitude. According to the results, participants who perceive danger and contamination and xenophobia as more stressful felt less gratitude.

\section{Hierarchical Regression Analyses}

The assumptions of the two regression analyses were tested to ensure statistical rigor. Initially, the scatter plots showed a linear relationship between the predictors and the criterion variable. Because some predictors were correlated (details in Table 3), a tolerance and variance inflation factor (VIF) analysis was conducted to assess collinearity. Assumption testing revealed that the collinearity assumption was not violated (negative quality of life Tolerance $\geq 0.44$, VIF $\leq 4.95$; gratitude Tolerance $\geq 0.20$, VIF $\leq 4.94$ ). Durbin-Watson was also used to determine whether the residual values were independent. The statistical value for negative quality of life was 1.75 and the statistical value for gratitude was 1.96 , indicating that the assumption of independent error was also met. Using the standardized residuals, we tested our final assumption about influential cases or outliers. The values obtained were all less than three, indicating that there were no outliers in the two regression analyses: negative quality of life (std residuals between -2.01 and 2.34) and gratitude (std residuals between -2.09 and 2.85).

The results of the hierarchical regression analysis are shown below in Table 4. For negative quality of life, women and number of dependents showed a significant contribution, $\mathrm{F}(7,191)=5.61, \mathrm{p}<.001$, accounting for $17 \%$ of the variance. COVID stress syndrome entered in Step 2, explained another $37 \%$ of the variance in negative quality of life, F (12, $186)=18.28, p<.001$. Socioeconomic status and xenophobia were small to moderate positive predictors of negative quality of life. On the other hand, none of the socio-demographic variables, with the exception of gender, significantly contributed to feelings of gratitude, suggesting that women
Table 3 Pearson Correlations between Study Variables

\begin{tabular}{llllllll}
\hline Variable & 1 & 2 & 3 & 4 & 5 & 6 & 7 \\
\hline 1. Danger \& Contamination & 1 & & & & & \\
2. Socioeconomic status & $.71^{* * *}$ & 1 & & & & \\
3. Xenophobia & $.69^{* * *}$ & $.38^{* * *}$ & 1 & & & \\
4. Traumatic Stress & $.41^{* * *}$ & $.20^{* *}$ & $.31^{* * *}$ & 1 & & \\
5. Checking Behaviour & $.59^{* * * *}$ & $.41^{* * *}$ & $.44^{* * *}$ & $.41^{* * *}$ & 1 & & \\
6. Negative QoL & $.54^{* * *}$ & $.25^{* * *}$ & $.66^{* * *}$ & $.38^{* * *}$ & $.39^{* * *}$ & 1 & \\
7. Gratitude & $-.14^{*}$ & -.07 & $-.29^{* * *}$ & -.02 & .02 & $-.16^{*}$ & 1 \\
\hline
\end{tabular}

$* p<.05 ; * * p<.01 ; * * * p<.001$ 
Table 4 Hierarchical Regression Analyses for Negative Quality of Life and Gratitude

\begin{tabular}{|c|c|c|c|c|c|c|c|c|}
\hline \multirow[t]{3}{*}{ Predictor } & \multicolumn{4}{|c|}{ NQOL } & \multicolumn{4}{|c|}{ Gratitude } \\
\hline & \multicolumn{2}{|c|}{ Step 1} & \multicolumn{2}{|c|}{ Step 2} & \multicolumn{2}{|c|}{ Step 1} & \multicolumn{2}{|c|}{ Step 2} \\
\hline & $\mathrm{b}$ & Beta & $\mathrm{b}$ & Beta & $\mathrm{b}$ & Beta & $\mathrm{b}$ & Beta \\
\hline Age & -.02 & -.14 & -.02 & -.16 & -.02 & -.20 & -.02 & -.15 \\
\hline Gender & .42 & $.29 * * *$ & .27 & $.19 * *$ & .33 & $.28 * * *$ & .40 & $.34 * * *$ \\
\hline Race & .03 & .02 & .05 & .03 & .16 & .13 & .16 & .13 \\
\hline Education & -.07 & -.03 & .05 & .02 & .06 & .03 & -.01 & .00 \\
\hline Relationship Status & .02 & .01 & .21 & .13 & .19 & .15 & .07 & .06 \\
\hline Income & .00 & .12 & .00 & -.05 & .00 & .01 & .00 & .05 \\
\hline Number of Dependents & .22 & $.31 * * *$ & .11 & $.16^{*}$ & .05 & .10 & .08 & .10 \\
\hline Danger \& Contamination & & & .19 & .18 & & & -.02 & -.03 \\
\hline Socioeconomic status & & & .20 & $.17 *$ & & & -.03 & -.03 \\
\hline Xenophobia & & & .37 & $.52 * * *$ & & & -.21 & $-.37 * * *$ \\
\hline Traumatic Stress & & & .63 & .11 & & & -.27 & -.06 \\
\hline Checking Behavior & & & .04 & .03 & & & .20 & .16 \\
\hline $\mathrm{R}^{2}$ Change & .17 & & .37 & & .13 & & .12 & \\
\hline
\end{tabular}

$* * p<.01 ; * * * p<.001$ generally reported higher levels of gratitude during the pandemic period, $F(7,191)=3.97, p<.001$. Xenophobia significantly predicted additional variance in gratitude, $\mathrm{F}(12$, $186)=5.11, \mathrm{p}<.001$

\section{Discussion}

The current study was conducted to assess the extent of COVID stress syndrome in Singaporeans who had been exposed to a pandemic outbreak associated with migrant worker dormitories. Participants reported low levels of pandemic-related stress in general, with the exception of xenophobia. They were particularly less concerned about risk of COVID-19 infection and socioeconomic status. Levels of traumatic stress and checking behaviour due to COVID-19 were also low. These findings may suggest that the government's disease prevention and control measures are competently helping the population to reduce anxiety and stress. This assertion is not unfounded as almost all (97\%) study participants trusted the government's ability to contain the pandemic. Higher levels of trust in the government have been shown to mitigate the emotional and psychological effects of the pandemic (Pedrosa et al., 2020). Singapore brands itself as a cosmopolitan city with strict, coherent policies and takes a top-down approach to tackling the pandemic (Lee et al., 2020; Tan et al., 2020). This has led to increasing compliance with COVID rules and decreasing scepticism about the development of the pandemic (Ngiam et al., 2021).

It is also noteworthy that among the COVID stressors, xenophobia was mentioned most frequently $(\mathrm{M}=2.59)$. The outbreak may have triggered xenophobic attitudes, as participants generally blamed migrants for the spread of the virus. This is not a novelty in history: During the Ebola outbreak, the population of West Africa was discriminated against in the United States (Monson, 2017). When the novel coronavirus emerged, the disease was initially referred to as the "Wuhan coronavirus" or "China virus," in part because the virus was first identified in Wuhan, China ( $\mathrm{Lu}$ et al., 2020). Racist incitement and xenophobic incidents have become increasingly common around the world, especially against Asians and people of Asian descent. Politicians' racist rhetoric against Asians exacerbates existing stigma and, as a result, systemic xenophobia (Pedrosa et al., 2020; Rich, 2020). Such stigmatization has recently been directed against migrant workers in Singapore, with an increasing number of COVID-19 confirmed cases in dormitories (Tai, 2020). Since the onset of the pandemic in Singapore, COVID-19 has infected nearly half (47\%) of migrant workers (Ministry of Health Singapore, 2020). Racist statements have been spread in the mainstream media, stereotypical portrayals in the media promote the perception of migrant workers as a public health threat (Tan et al., 2021). An opinion piece attributed the spread of COVID-19 in dormitories to the poor personal hygiene habits of migrant workers who come from "backward countries" (Yi et al., 2021). Accepting false beliefs as true can reinforce xenophobic tendencies in society (Han et al., 2018; McCauley et al., 2013). Stricter policies need to be put in place to limit false claims against migrant workers.

Additionally, the mean composite score for negative quality of life was 2.26 , which corresponded to a mediocre negative quality of life. The score was much lower compared 
to norms documented in other populations studied, such as nursing students ( $\mathrm{M}=3.35$; Guillasper et al., 2021), teachers ( $M=2.75$; Rabacal et al., 2020), a non-clinical sample $(M=2.91$; Repišti et al., 2020), and patients with severe mental illness ( $M=2.40$; Repišti et al., 2020). This difference in mean score between countries is considered to be the result of culturally different perceptions of quality of life, but also of sampling factors. Surprisingly, reported gratitude was generally high $(M=5.56)$, and significantly higher than the scale's midpoint. The gratitude score in our study appears to be similar to that of a recent local study ( $\mathrm{M}=4.31$; Tong $\& \mathrm{Oh}, 2021)$. The reason for the observed high gratitude levels during difficult times could be multifactorial. First, it has been demonstrated that appreciating something of value is one way to feel gratitude (Emmons \& McCullough, 2003). While it may seem nearly impossible to find reasons to be grateful during the pandemic. In this study, only $5 \%$ of participants lost their job or salary as a result of COVID-19 and $0.5 \%$ of participants reported a COVID-19 infection in an acquaintance. A low risk of infection and a low proportion of job loss could help participants maintain gratitude (Tan et al., 2020). Second, before the coronavirus crisis, the world seemed to run with an everyday sense of urgency and living life at rocket speed was the norm. In today's fastpaced world, people may not always take the time to express gratitude, so the positive aspects of life are overlooked and ignored (Emmons \& McCullough, 2003). As the pandemic has slowed our frenetic pace of life, people may have more time to carve out a slice of gratitude (Oliveira et al., 2021; Tong \& Oh, 2021).

Furthermore, all domains of the COVID Stress Scales were intercorrelated, meaning that symptoms measured by each scale tended to occur together (Taylor et al., 2020). Positive correlations were found between COVID stress syndrome and negative quality of life. This means that the stressful feeling resulting from COVID can affect the quality of life (Wu et al., 2021). Nevertheless, only danger and contamination and xenophobia showed a negative relationship with gratitude. This is supported by the findings of Wood et al. (2010), who found that coping with pandemic fear and hatred blocked showing gratitude.

To explore this further, we conducted some additional analyses examining the role of COVID-19 stress syndrome on negative quality of life and gratitude, after controlling for sociodemographic controls. Being women, having more dependents, worrying about socioeconomic status, and xenophobia led to lower quality of life. The finding that women appeared to be more vulnerable to negative quality of life is again consistent with the literature (Guillasper et al., 2021; Repišti et al., 2020). Moreover, caregivers exhibited lower quality of life than adults who did not play this role. These findings are consistent with previous research that found that the prevalence of anxiety and stress was higher among family caregivers during the pandemic because they had to take on other responsibilities such as housework, helping children with schoolwork, etc. (Agberotimi et al., 2020; Bridgland et al., 2021; Poudel \& Subedi, 2020). Multitasking can be exhausting, and is often managed differently by men and women, which may explain gender differences in quality of life (Rabacal et al., 2020). More research on caregiver coping styles and behaviours may help develop supports and services to meet caregivers' needs during and after the pandemic. Participants who reported socioeconomic pressures also had lower quality of life. The finding is not surprising given that the ongoing COVID-19 pandemic has caused a systemic economic crisis in a variety of industries (Pedrosa et al., 2020). Unemployment is on the rise, and even former professionals with steady jobs are at risk of losing their jobs (Heath, 2020). Aside from the unemployment rate, a crisis plan may include wage cuts, reduced work hours, and increased work demand. A second regression analysis showed that only male gender and xenophobia predicted lower gratitude. In particular, men in this study, reported feeling less gratitude than women. Previous research has found that gender matters when it comes to gratitude (Alkozei et al., 2018; Kashdan et al., 2009). It has been observed that women are more likely than men to feel and express gratitude. Men, on the other hand, may be reluctant to express gratitude because it could be a sign of a lack of autonomy, and its expression could be perceived as dependence on others.

Xenophobia proved to be the strongest predictor of negative quality of life and gratitude. The study found that xenophobia not only affected quality of life, but also levels of gratitude. Since most previous studies have only looked at victims and rarely at haters, we have to wonder how xenophobia can cause people to be les grateful and have a lower quality of life. A logical explanation can only be drawn by understanding the word xenophobia. The word comes from Latin and means fear of others, and in particular fear of foreigners. This study took place when Singapore was dealing with outbreaks related to migrant worker dormitories. The stress from these types of events is completely unpredictable, unforeseen, and completely beyond the control of the individuals, and as a result, their stress levels increased significantly (Tai, 2020; Yi et al., 2021). There is probably a link between stress and blaming others due to "intolerance to uncertainty." According to scholars, blaming others or scapegoating serves to resolve one's sense of control in times of crisis, especially when one's well-being is threatened, which can lead to an escalation of racism, mistrust, and xenophobia (Boelen \& Carleton, 2012; Monson, 2017). Fear of migrant workers as "virus carries" may have heightened people's awareness of the problems they bring, leading to a low quality of life (Chui, 2020; Rich, 2020). Fear is not the only emotion involved in identifying xenophobia. Hatred and 
resentment may also be present (Yi et al., 2021). Before the pandemic, there is resentment among the locals towards the group of foreigners who they believe will take away their jobs (Tai, 2020). Chinese, Filipinos and South Asians are among the main immigrant groups, that are often perceived by citizens as cultural and economic threats, with overpopulation contributing to a sense of unease (Tai, 2020). The pandemic has undoubtedly increased economic pressures on the general population. Apart from the perception that elite migrants steal resources such as jobs, foreigners may appear to live in a higher standard of living than the typical Singaporean because they own condominiums and send their children to private schools, even if it is because they do not have access to public schools (Yi et al., 2021). A similar discussion is also taking place online, where sensationalist examples of foreigners being treated well in Singapore fuel xenophobia (Tai, 2020). Perceptions of greater resentment and anger can make it harder for individuals to appreciate the good things in their lives (Watkins et al., 2003).

\section{Implications}

This is the first study to use psychometrically valid measures to assess COVID stress syndrome, quality of life, and gratitude during the COVID-19 pandemic in Singapore. Fear of danger and contamination, socioeconomic status consequences, xenophobia, compulsive checking, and seeking assurance reflect the relationship between stressors triggered by COVID. Thus, the findings provide an indication of how such a relationship affects a person's quality of life and gratitude. In this study, the social implications can be viewed through the fact that policing migrants remains a systemic problem. Despite Singapore's claim to be a tolerant and fair society, discriminatory attitudes persist in public opinion, laws, and policies. In reality, the movement of migrant workers is still restricted, although restrictions on the general Singaporean population have become looser following the April 2020 dormitory outbreak (Yi et al., 2021). Restricting the movement of migrant workers and imposing quarantine regulations reinforce the misconception that they are dangerous and contagious (Wang et al., 2020). Nevertheless, lack of space, poor ventilation and overcrowding make it difficult for workers to comply with safety measures, leading to an increased risk of infection (Ngiam et al., 2021). Overcoming xenophobia requires education, community engagement, dialogue, leadership, and laws and policies to create a truly inclusive and respectful society. Another interesting finding of this study was that xenophobia was the strongest predictor of poor quality of life and gratitude. This study fills an educational and research gap in the field of mental health. The findings from this study could enable effective applications that facilitate gratitude and quality of life. By eliminating xenophobia, people may adopt a more growth-oriented lifestyle as they adopt a more inclusive attitude and perspective. Interventions that promote appreciation and acceptance of others' differences can improve gratitude and enhance quality of life.

\section{Limitations}

This study also has limitations. First, due to the crosssectional design, we did not have information on quality of life and gratitude before the outbreak, and we could not test causality between the studied associations. Second, the use of self-report scales may be biased by the threatening nature of the pandemic, which could lead participants to exaggerate their responses. Third, because the data were collected during the pandemic outbreak period in the context of migrant worker dormitories, the results could differ from those obtained at times when more community cases occurred. Fourth, online recruitment could introduce some selection bias, such that the sample was heavily skewed towards educated individuals and may have excluded individuals with lower socioeconomic and educational status. This may explain why most COVID stress syndrome scores were low in this study. Finally, the overall quality of life was assessed in this study. Future research could examine different various aspects of quality of life to reach a definitive conclusion.

\section{Conclusion}

Overall, pandemic-related stress levels among study participants in Singapore were generally low, albeit within normal limits. The sample exhibited low levels of fear of COVID19 and contagion, socioeconomic impact, checking and reassurance seeking, and traumatic stress symptoms. Yet, xenophobia and stigmatization of migrant workers increased during the pandemic, leading to even worse mental health outcomes for the population. Xenophobia, along with gender, number of dependents, and socioeconomic concerns, was associated with negative psychological outcomes such as low quality of life and gratitude. The associated factors discovered in this study may help in the development of appropriate interventions for the general population in Singapore to improve their quality of life and gratitude during the pandemic. Although these findings are preliminary, they support further investigation of xenophobia in the context of the COVID-19 pandemic. Future research is needed to determine the full extent of COVID-related xenophobia and how it evolves as the pandemic progresses.

Availability of Data and Material The data that support the findings of this study are available from the corresponding author upon reasonable request. 
Code Available Not applicable.

Authors' Contributions First and second authors contributed to the design and implementation of the research, to the analysis of the results and to the writing of the manuscript.

\section{Declarations}

Conflict of Interest The authors declare that they have no conflict of interest.

Ethical Approval All procedures performed in studies involving human participants were in accordance with the ethical standards of the institutional and/ or national research committee and with the 1964 Helsinki declaration and its later amendments or comparable ethical standards.

Consent to Participate Informed consent was obtained from all individual participants recruited in the study.

Consent for Publication All authors read the final version of the paper and give full consent for this paper to be published.

\section{References}

Agberotimi, S. F., Akinsola, O. S., Oguntayo, R., \& Olaseni, A. O. (2020). Interactions between socioeconomic status and mental health outcomes in the Nigerian context amid COVID-19 pandemic: A comparative study. Frontiers in Psychology, 11, 559819. https://doi.org/10.3389/fpsyg.2020.559819

Alkozei, A., Smith, R., \& Killgore, W. D. S. (2018). Gratitude and subjective wellbeing: A proposal of two casual frameworks. Journal of Happiness Studies, 19, 1519-1542. https://doi.org/ 10.1007/s10902-017-9870-1

American Psychiatric Association. (2013). Diagnostic and statistical manual of mental health disorders $\left(5^{\text {th }} \mathrm{ed}\right)$. Arlington.

Ang, C. S. (2020). Anxiety in Malaysian children and adolescents: Validation of the screen for child anxiety related emotional disorders (SCARED). Trends in Psychiatry and Psychotherapy, 42(1), 7-15. https://doi.org/10.1590/2237-6089-2018-0109

Arndt, J., Solomon, S., Kasser, T., \& Sheldon, K. M. (2004). The urge to splurge: A terror management account of materialism and consumer behavior. Journal of Consumer Psychology, 14, 198-212. https://doi.org/10.1207/s15327663jcp1403_2

Bagdasarian, N., \& Fisher, D. (2020). Heterogenous COVID-19 transmission dynamics within Singapore: A clearer picture of future national responses. BMC Medicine, 18(1), 1-3. https:// doi.org/10.1186/s12916-020-01625-7

Boelen, P. A., \& Carleton, R. N. (2012). Intolerance of uncertainty, hypochondriacal concerns, obsessive-compulsive symptoms, and worry. The Journal of Nervous and Mental Disease, 200(3), 208-213. https://doi.org/10.1097/NMD.0b013e318247cb17

Bridgland, V., Moeck, E. K., Green, D. M., Swain, T. L., Nayda, D. M., Matson, L. A., Hutchison, N. P., \& Takarangi, M. (2021). Why the COVID-19 pandemic is a traumatic stressor. PLoS One, 16(1), e0240146. https://doi.org/10.1371/journal.pone. 0240146

Cabarkapa, S., Nadjidai, S. E., Murgier, J., \& Ng, C. H. (2020). The psychological impact of COVID-19 and other viral epidemics on frontline healthcare workers and ways to address it: A rapid systematic review. Brain, Behavior, \& Immunity Health, 8, 100144. https://doi.org/10.1016/j.bbih.2020.100144
Cella, D. F. (1994). Quality of life: Concepts and definition. Journal of Pain and Symptom Management, 9(3), 186-192. https://doi. org/10.1016/0885-3924(94)90129-5

Centers for Disease Control and Prevention. (2021). Novel coronavirus, Wuhan, China. Retrieved from https://www.cdc.gov/coron avirus/2019-ncov/index.html on 14 July 2021.

Chui, A. (2020). Trump has no qualms about calling coronavirus the "Chinese virus". That's a dangerous attitude, experts say. The Washington Post. Retrieved from: https://www.washington post.com/nation/2020/03/20/coronavirus-trump-chinese-virus/ on 15 June 2021.

De Kock, J. H., Latham, H. A., Leslie, S. J., Grindle, M., Munoz, S.-A., Ellis, L., Polson, R., \& O'Malley, C. M. (2021). A rapid review of the impact of COVID-19 on the mental health of healthcare workers: Implications for supporting psychological well-being. BMC Public Health, 21, 104. https://doi.org/10. 1186/s12889-020-10070-3

El-Terk, N. (2020). Toilet paper, canned food: What explains coronavirus panic buying. Aljazeera. Retrieved from https://www. aljareeza.com/news/2020/03/toilet-paper-canned-food-expla ins-coronavirus-panic-buying-200313083341035.html on 1 August 2021.

Emmons, R. A., \& McCullough, M. E. (2003). Counting blessings versus burdens: An experiential investigation of gratitude and subjective well-being in daily life. Journal of Personality and Social Psychology, 84, 337-389. https://doi.org/10.1037/00223514.84.2.377

International Labour Organization, (2020). Almost 25 Million Jobs could be Lost Worldwide as a Result of COVID-19, say ILO. Retrieved from https://www.ilo.org/global/about-the-ilo/newsr oom/news/WCMS 738742/lang-en/index.htm on 27 September, 2021.

Gallo, W. T., Bradley, E. H., Siegel, M., \& Kasl, S. V. (2000). Health effects of involuntary job loss amongst older workers: Findings from the health and retirement survey. The journals of gerontology. Series B, Psychological Sciences and Social Sciences, 55, S131-S140. https://doi.org/10.1093/geronb/55.3.s131

Guillasper, J., Oducado, R. M., \& Soriano, G. (2021). Protective role of resilience on COVID-19 impact on the quality of life of nursing students in the Philippines. Belitung Nursing Journal, 7(1), 43-49. https://doi.org/10.33546/bnj.1297

Han, P., Zikmund-Fisher, B. J., Duarte, C. W., Knaus, M., Black, A., Scherer, A. M., \& Fagerlin, A. (2018). Communication of scientific uncertainty about a novel pandemic health threat: Ambiguity aversion and its mechanisms. Journal of Health Communication, 23(5), 435-444. https://doi.org/10.1080/10810730.2018.1461961

Harvey, A. P., Fuhrmeister, E. R., Cantrell, M., Pitol, A. K., Swarthout, J. M., Powers, J. E., Nadimpalli, M. L., Julian, T. R., \& Pickering, A. J. (2020). Longitudinal monitoring of SARS-CoV-2 RNA on high-touch surfaces in a community setting. medRxiv: The preprint server for health sciences, 2020.10.27.20220905. https://doi. org/10.1101/2020.10.27.20220905.

Heath, S. (2020). Socioeconomic status tied to mental health during coronavirus. Patient engagement hit. Retrieved from https://patie ntengagementhit.com/news/socioeconomic-status-tied-to-mentalhealth-during-coronavirus on 27 June 2021.

Israel-Cohen, Y., Uzefovsky, F., Kashy-Rosenbaum, G., \& Kaplan, O. (2015). Gratitude and PTSD symptoms among Israeli youth exposed to missile attacks: examining the mediation of positive and negative affect and life satisfaction. Journal of Positive Psychology, 10(2), 99-106. https://doi.org/10.1080/17439760. 2014.927910

Jans-Beken, L. (2021). A perspective on mature gratitude as a way of coping with COVID-19. Frontiers in Psychology, 12, 632911. https://doi.org/10.3389/fpsyg.2021.632911 
Jassi, A., Shahriyarmolki, K., Taylor, T., Peile, L., Challacombe, F., Clark, B., \& Veale, D. (2020). OCD and COVID-19: A new frontier. The Cognitive Behaviour Therapist, 13, E27. https://doi.org/ 10.1017/S1754470X20000318

Kampf, G., Brüggemann, Y., Kaba, H., Steinmann, J., Pfaender, S., Scheithauer, S., \& Steinmann, E. (2020). Potential sources, modes of transmission and effectiveness of prevention measures against SARS-CoV-2. The Journal of Hospital Infection, 106(4), 678697. https://doi.org/10.1016/j.jhin.2020.09.022

Kang, D., Choi, H., Kim, J., \& Choi, J. (2020). Spatial epidemic dynamics of the COVID-19 outbreak in China. International Journal of Infectious Diseases, 94, 96-102. doi: 10.1016/j. ijid.2020.03.076.pmid: 32251789.

Kashdan, T. B., Mishra, A., Breen, W. E., \& Froh, J. J. (2009). Gender differences in gratitude: Examining appraisals, narratives, the willingness to express emotions, and changes in psychological needs. Journal of Personality, 77(3), 691-730. https://doi.org/10. 1111/j.1467-6494.2009.00562.x

Kashdan, T. B., Uswatte, G., \& Julian, T. (2006). Gratitude and hedonic and eudaimonic well-being in Vietnam war veterans. Behaviour Research and Therapy, 44(2), 177-199. https://doi.org/10.1016/j. brat.2005.01.005

Lee, V. J., Chiew, C. J., \& Khong, W. X. (2020). Interrupting transmission of COVID-19: Lessons from containment efforts in Singapore. Journal of Travel Medicine, 27(3), taaa039. https://doi.org/ 10.1093/jtm/taaa039

Liang, L., Gao, T., Ren, H., Cao, R., Qin, Z., Hu, Y., Li, C., \& Mei, S. (2020). Post-traumatic stress disorder and psychological distress in Chinese youths following the COVID-19 emergency. Journal of Health Psychology, 25(9), 1164-1175. https://doi.org/10.1177/ 1359105320937057

Liu, M., Zhang, H., \& Huang, H. (2020). Media exposure to COVID-19 information, risk perception, social and geographical proximity, and self-rated anxiety in China. BMC Public Health, 20, 1649. https://doi.org/10.1186/s12889-020-09761-8

Lu, H., Stratton, C. W., \& Tang, Y. W. (2020). Outbreak of pneumonia of unknown etiology in Wuhan, China: The mystery and the miracle. Journal of Medical Virology., 92, 401-402. https://doi. org/10.1002/jmv.25678

McCauley, M., Minsky, S., \& Viswanath, K. (2013). The H1N1 pandemic: Media frames, stigmatization and coping. BMC Public Health, 13, 1116. https://doi.org/10.1186/1471-2458-13-1116

Ministry of Health Singapore (2020). Measures to contain the covid-19 outbreak in migrant worker dormitories. Retrieved from https:// www.moh.gov.sg/news-highlights/details/measures-to-conta in-the-covid-19-outbreak-in-migrant-worker-dormitories on 30 September 2021.

Monson, S. (2017). Ebola as African: American media discourses of panic and Otherization. Africa Today, 63(3), 3-27. https://doi.org/ 10.2979/africatoday.63.3.02

Muller, A. E., Hafstad, E. V., Himmels, J. P. W., Smedslund, G., Flottorp, S., Stensland, S. Ø., Strootbants, S., Van de Velde, S., \& Vist, G. E. (2020). The mental impact of the covid-19 pandemic on healthcare workers, and interventions to help them: A rapid systematic review. Psychiatry Research, 293, 113441. https://doi. org/10.1016/j.psychres.2020.113441

Ngiam, J. N., Chew, N., Tham, S. M., Beh, D. L., Lim, Z. Y., Li, T., Cen, S., Tambyah, P. A., Santosa, A., Sia, C. H., \& Cross, G. B. (2021). Demographic shift in COVID-19 patients in Singapore from an aged, at-risk population to young migrant workers with reduced risk of severe disease. International journal of infectious diseases: IJID: official publication of the International Society for Infectious Diseases, 103, 329-335. https://doi.org/10.1016/j. ijid.2020.11.157
Oliveira, R., Baldé, A., Madeira, M., Ribeiro, T., \& Arriaga, P. (2021). The impact of writing about gratitude on the intention to engage in prosocial behaviors during the COVID-19 outbreak. Frontiers in Psychology, 12, 588691. https://doi.org/10.3389/fpsyg.2021. 588691

Pedrosa, A. L., Bitencourt, L., Fróes, A., Cazumbá, M., Campos, R., de Brito, S., Silva, S. E., \& A. C. (2020). Emotional, behavioral, and psychological impact of the COVID-19 pandemic. Frontiers in Psychology, 11, 566212. https://doi.org/10.3389/fpsyg.2020. 566212

Perrin, P. C., McCabe, O. L., Everly Jr., G. S., \& Links, J. M. (2009). Preparing for an influenza pandemic: Mental health considerations. Prehospital and Disaster Medicine, 24(3), 223-230. https:// doi.org/10.1017/s1049023x00006853

Pfefferbaum, B., \& North, C. S. (2020). Mental health and the Covid19 pandemic. The New England Journal of Medicine, 383(6), 510-512. https://doi.org/10.1056/NEJMp2008017

Poudel, K., \& Subedi, P. (2020). Impact of COVID-19 pandemic on socioeconomic and mental health aspects in Nepal. International Journal of Social Psychiatry, 66(8), 748-755. https://doi.org/10. 1177/0020764020942247

Rabacal, J., Oducado, R. M., \& Tamdang, K. (2020). COVID-19 impact on the quality of life of teachers: A cross-sectional study. Asian journal for public opinion research, 8(4), 478-492. 2020. https://doi.org/10.15206/ajpor.2020.8.4.478.

Ren, S. Y., Gao, R. D., \& Chen, Y. L. (2020). Fear can be more harmful than the severe acute respiratory syndrome coronavirus 2 in controlling the corona virus disease 2019 epidemic. World Journal of Clinical Cases, 8(4), 652-657. https://doi.org/10.12998/wjcc. v8.i4.652

Repišti, S., Jovanović, N., Kuzman, M. R., Medved, S., Jerotić, S., Ribić, E., et al. (2020). How to measure the impact of the COVID19 pandemic on quality of life: COV19-QoL -the development, reliability and validity of a new scale. Global Psychiatry, 3(2), 201-210. https://doi.org/10.2478/gp-2020-0016

Rich, M. (2020). As coronavirus spreads, so does anti-chinese sentiment. The New York times. Retrieved from https://www.nytimes. com/2020/01/30/world/asia/coronavirus-chinese-racism.html on 15 July 2021.

Singapore tops ranking of world's best places to be amid Covid-19 pandemic. (2021, April 21). The Straits Times. Retrieved from https://www.straitstimes.com/asia/the-best-and-worst-places-tobe-in-the-world-as-covid-19-variants-outrace-vaccinations on 31 May 2021.

Tai, J. (2020). Racism and xenophobia resurfacing during Covid-19: MCCY minister grace Fu. The Straits Times. Retrieved from https://www.straitstimes.com/singapore/racism-and-xenophobiaresurfacing-during-covid-19-mccy-minister-grace- on 31 May 2021.

Tan, J. B., Cook, M. J., Logan, P., Rozanova, L., \& Wilder-Smith, A. (2020). Singapore's pandemic preparedness: An overview of the first wave of COVID-19. International Journal of Environmental Research and Public Health, 18(1), 252. https://doi.org/10.3390/ ijerph18010252

Tan, I. B., Tan, C., Hsu, L. Y., Dan, Y. Y., Aw, A., Cook, A. R., \& Lee, V. J. (2021). Prevalence and outcomes of SARS-CoV-2 infection among migrant workers in Singapore. JAMA, 325(6), 584-585. https://doi.org/10.1001/jama.2020.24071

Taylor, S., Landry, C. A., Paluszek, M. M., Fergus, T. A., McKay, D., \& Asmundson, G. J. G. (2020). Development and initial validation of the COVID stress scales. Journal of Anxiety Disorders, 72, 102232. https://doi.org/10.1016/j.janxdis.2020.102232

Teo, W. Z. Y., Yap, E. S., Yip, C., Ong, L., \& Lee, C.-. T. (2020). The psychological impact of COVID-19 on 'hidden' healthcare 
workers. International Journal of Social Psychiatry, 67(3), 284289. https://doi.org/10.1177/0020764020950772

Tong, E., \& Oh, V. (2021). Gratitude and adaptive coping among Chinese Singaporeans during the beginning of the COVID-19 pandemic. Frontiers in Psychiatry, 11, 628937. https://doi.org/10. 3389/fpsyt.2020.628937

Wang, C., Pan, R., Wan, X., Tan, Y., Xu, L., McIntyre, R. S., Choo, F. N., Tran, B., Ho, R., Sharma, V. K., \& Ho, C. (2020). A longitudinal study on the mental health of general population during the COVID-19 epidemic in China. Brain, Behavior, and Immunity, 87, 40-48. https://doi.org/10.1016/j.bbi.2020.04.028

Watkins, P. C., Woodward, K., Stone, T., \& Kolts, R. L. (2003). Gratitude and happiness: Development of a measure of gratitude and relationships with subjective well-being. Social Behavior and Personality: An International Journal, 31(5), 431-452. https:// doi.org/10.2224/sbp.2003.31.5.431

Wood, A. M., Froh, J. J., \& Geraghty, A. W. A. (2010). Gratitude and well-being: A review and theoretical integration. Clinical Psychology Review, 30, 890-905. https://doi.org/10.1016/j.cpr. 2010.03.005

World Health Organization. (2020). Situation reports coronavirus. World Health Organization. Retrieved from https://www.who. int/emergencies/diseases/novel-coronavirus-2019/siuation-repor ts on 30 September 2021.
Worldometer Statistics (2021). Total coronavirus cases in the world. Retrieved from: https://www.worldometers.info/coronavirus/ on 30 September 2021

Wu, T., Jia, X., Shi, H., Niu, J., Yin, X., Xie, J., \& Wang, X. (2021). Prevalence of mental health problems during the COVID-19 pandemic: A systematic review and meta-analysis. Journal of Affective Disorders, 281, 91-98. https://doi.org/10.1016/j.jad.2020.11. 117

Xiong, J., Lipsitz, O., Nasri, F., Lui, L., Gill, H., Phan, L., Chen-Li, D., Iacobucci, M., Ho, R., Majeed, A., \& McIntyre, R. S. (2020). Impact of COVID-19 pandemic on mental health in the general population: A systematic review. Journal of Affective Disorders, 277, 55-64. https://doi.org/10.1016/j.jad.2020.08.001

Yi, H., Ng, S. T., Farwin, A., Pei Ting Low, A., Chang, C. M., \& Lim, J. (2021). Health equity considerations in COVID-19: Geospatial network analysis of the COVID-19 outbreak in the migrant population in Singapore. Journal of Travel Medicine, 28(2), taaa159. https://doi.org/10.1093/jtm/taaa159

Publisher's Note Springer Nature remains neutral with regard to jurisdictional claims in published maps and institutional affiliations. 